\title{
Comparative vibration analysis on IC engine with biodiesel and multi-walled carbon nanotube
}

\author{
Velumani $V^{1}$, Manieniyan $V^{2}$, Sivaprakasam $S^{3}$ \\ ${ }^{1}$ Mechanical Engineering, Podhigai College of Engineering and Technology, Tamilnadu, India \\ ${ }^{2}$ Mechanical Engineering, Government College of Engineering, Srirangam, India \\ ${ }^{3}$ Mechanical Engineering, Annamalai University, Tamil Nadu, India \\ ${ }^{1}$ Corresponding author \\ E-mail: ${ }^{1}$ velu9442857898@gmail.com, ${ }^{2}$ manieniyan78@gmail.com, ${ }^{3}$ rgssiva2002@yahoo.co.in
}

Received 16 December 2018; received in revised form 4 March 2019; accepted 12 March 2019

DOI https://doi.org/10.21595/jve.2019.20459

Check for updates

Copyright $₫ 2019$ Velumani V, et al. This is an open access article distributed under the Creative Commons Attribution License, which permits unrestricted use, distribution, and reproduction in any medium, provided the original work is properly cited.

\begin{abstract}
Sound and vibration caused in the engine due to combustion process may affect the users. One of the vital qualities of diesel fuel is high sound and vibration. The vibration of the engine is one of the primary factors in engine structure and maintenance. Vibration estimation on the engine block, cylinder head is a non-intrusive strategy and has been utilized effectively for fault prediction of diesel engines. The vibration signals along with signal processing techniques are utilized to highlights the features that are sensitive to faults. In this work, experimental tests have been carried out to assess the vibration of a diesel engine with diesel, $20 \%$ biodiesel (Ethyl Ester of ground nut acid oil EEGOA) and $30 \mathrm{ppm}$ Multi-walled Carbon Nano tubes with $20 \%$ biodiesel (MWCNT30ppm B20EEGAO) at various load (20\%, $40 \%, 60 \%, 80 \%$ and $100 \%)$. Digital Vibration Meter Model: Equinox-VM 6360 is utilized to gauge the vibration in three unique positions, one is cylinder head of the engine, second one is crank of the engine, and third one is bottom of the engine. In this work, the vibration is measured in terms of acceleration. The MWCNT30ppm B20EEGAO blend demonstrates the lower vibration compared with different blends.
\end{abstract}

Keywords: biodiesel, carbon nano tube, engine, vibration.

\section{Introduction}

Generally, the fossil fuel engines have been used in transport in almost all vehicles. Due to the fast depletion of fossil fuels and the increasingly strict emission laws, there is an urgent need to find alternatives to fossil fuels. The vegetable oil is most suitable alternate fuel for diesel fuel. While using the vegetable oil in diesel engine, it results in the lower thermal efficiency, besides being it produces the same power output [1]. The emission is the major problem in diesel engine. Decreasing the engine emission and environment protection by using vegetable oil is the recent focus of biodiesel research. The properties of the vegetable oil are almost closer to diesel fuel, so it is very much suitable for alternative fuel for diesel engine [2, 3]. It can be directly used in diesel engine with out any modification. Vegetable oil have higher flash point and high cetane number, hence it runs the diesel engine with safe. It has more oxygen, carbon and hydrogen molecule, similar to diesel fuel. But it has longer molecule structure compared to diesel fuel, thus leads to higher viscosity. Higher viscosity affects the injection parameter of the engine. The higher viscosity is reduced by the tranesterification process. The carbon residue of vegetable oil is higher than that of diesel, which leads to smoky exhaust in a diesel engine [4].

The elongated molecular chain, less cetane number and reduced volatility results in enhanced ignition feature in case of Vegetable oils. The higher oxygen content in the vegetable oils ends up in lesser calorific value. On the other hand, the outsized molecular mass and chemical structure is the cause for higher viscosity and carbon residue. The indication of vegetable oil as safe oil to stock up is due to their higher flash point than diesel. The cold point is much larger for vegetable oil as they are denser, due to which the vegetable oil freezes at small ambient temperatures [5]. When such vegetable oils are fueled into the engine, the lesser volatility causes slow evaporation 
compared to diesel. Based on the composition, the cetane number of vegetable oil ranges from 35 to 50 , which is almost nearer to the cetane number of diesel.

Jindal [6] analyzed on employing the vibration signatures on the engine cylinder and engine head. He analyzed the effect of vibration in an engine fueled with both diesel and biodiesel blends. The analysis was carried out by varying the compression ratio and injection pressures. The results proved a noteworthy effect in the vibration output and the variation is used to evaluate the long term effects. His research focused on essential relationship between the engine vibration pattern and the combustion process under diverse operating conditions. AhmadTaghizadeh Alisaraei et al. [7] in his work used a single differential tractor with four stroke and six cylinder engine for evaluation. The vibration analysis was carried out for biodiesel and various biodiesel blends. Statistical analysis of the experimental result depicts that the measured value of vibration was least for B40 and B20. Furthermore, the biodiesel blends B15, B30 and B50 recorded the high values in vibration. Also, the results derive that, at various engine speeds, vibration remains consistent with power torque curve. Wongchai et al. [8] considered the application of an engine block vibration transducer. The focus of his work was to achieve a real time management of the control unit using the vibration signal as a response to accurate the injection parameters. They experimented on a tiny displacement two cylinder common rail diesel engines fueled with various biodiesel blends. Ftoutou Ezzeddine and Mnaouar Chouchane [9] focused on vibration analysis for early detection of fuel injection faults in an internal combustion diesel engine with six cylinders in line. The result shown the cylinder head are shown to be useful for the detection of injection faults.

A significant part of the research in the literature of bio diesel center around the engine performance estimated through thermal efficiency, power output, specific fuel consumption, emissions, etc. The long term impacts are yet to be examined. The unpredictable ignition inside the combustion chamber brings about knocking and results in harm to the ignition chamber and cylinder head $[10,11]$. This makes the engine to vibrate, all the more prompting early failure of structures and parts. Subsequently to envision the prerequisites and nature of burning in the cylinder of CI engine, vibration signature may give a solid diagnostic tool. The vibration caused in any machine because of its moving parts is for the most of low frequency $[12,13]$. On occasion high frequency vibrations are likewise present in IC engine because of unusual combustion of charge. Vibrations delivered in diesel engine are predominantly in two ways, vibrations in lateral direction and vibrations in longitudinal way. The cylinder affect on the chamber liner is known as cylinder slap. The cylinder slap is the wellspring of vibrations sidelong way. Lateral vibrations drives results in more prominent wear of cylinder and liner surface and this wear impact is more contrasted with longitudinal vibrations $[14,15]$.

\section{Experimental investigation}

The vibration analysis was carried out in the kirlosker TV1 engine. The specification of the engine is as shown in Table 1. The Fig. 1 shows the experimental arrangement. The eddy current dynamometer was used as a loading device. The loading device was controlled by the control panel. The experiments were conducted at constant speed at $1500 \mathrm{rpm}$. Experimental tests have been carried out to evaluate the vibration of a diesel engine when fueled with diesel, $20 \%$ biodiesel (Ethyl Ester of ground nut acid oil EEGOA) and Multi-walled Carbon Nano tubes with $20 \%$ biodiesel (MWCNT30ppm B20EEGAO) at different load (20\%, $40 \%, 60 \%, 80 \%$ and $100 \%)$. The biodiesel was obtained from by-product of vegetable oil refinery industry waste of Ground nut Acid Oil in transesterification process with ethyl ester of ground nut acid oil. The vibration of the engine was measured at three different position such as engine head, engine crank and engine bottom. The vibration was measured by using digital Vibration Meter Model: Equinox-VM 6360 . In this research, a portable model of vibration meter is used to measure the vibration of small machine. It exploits an external accelerometer and magnetic base to improve frequency response and provide a more repeatable vibration reading. 


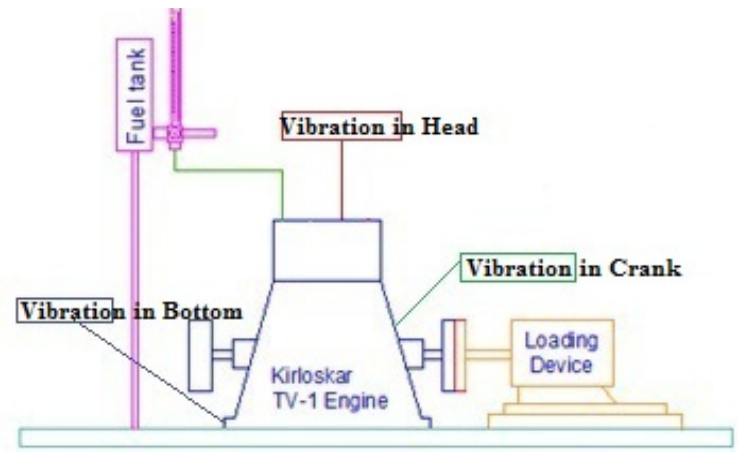

Fig. 1. Test engine

Table 1. Specification of engine

\begin{tabular}{|c|c|}
\hline Type & Vertical inline diesel engine, 4 stroke, water cooled \\
\hline No of cylinder & Single cylinder \\
\hline Bore $\times$ stroke & $87.5 \mathrm{~mm} \times 110 \mathrm{~mm}$ \\
\hline Compression ratio & $17.5: 1$ \\
\hline Brake power & $5.2 \mathrm{Kw}$ \\
\hline Speed & $1500 \mathrm{rpm}$ \\
\hline Dynamometer & Eddy current \\
\hline Ignition timing & $23^{\circ} \mathrm{bTDC}$ (rated) \\
\hline
\end{tabular}

\section{Result and discussion}

The results and discussion are carried out in analyzing the engine vibration with diesel, B20EEGAO and B20EEGAOMWCNT30ppm. The engine vibration is measured in terms of acceleration. The measurement of knocking in the combustion chamber is very more complex. The knocking is measured by combustion parameters. The combustion parameter is usually measured using pressure sensor and by making a hole in cylinder head, which is very complex and costliest method. So, in our analysis, the signal analysis is used to measure the combustion status in combustion chamber of engine without affecting the cylinder head. In this experiment, vibration signal is used in terms of acceleration. For this experimental analysis conducted, the engine was subjected to run for 30 minutes for each load. The vibration is measured during this run time of 30 minutes. The graphical representations are given in Fig. 2-Fig. 19 for the peak vibration noted for each load. The graph drawn is for only 10 seconds that accounts for peak vibration to happen.

\subsection{Vibration analysis with diesel}

With the estimation of acceleration from Fig. 2 to 7 , it is observed that in diesel in three different places of the engine such as head, crank and bottom; the acceleration is minimal in the $20 \%$ load. In Table 2, the mean and maximum of vibration result for head, crank and bottom is observed at $20 \%$ load and $100 \%$ load. The lesser viscosity of diesel fuel is because of better atomization and homogeneous air fuel mixture property. This results in complete combustion and reduces the ignition delay. Shorter delay period may cause reduction of acceleration of the engine $[1,16]$. The variation of acceleration mainly depends on combustion characteristics such as cylinder pressure and ignition delay. The mean acceleration was noted in head $169.59 \mathrm{~kJ} / \mathrm{m}^{3}$, crank $106.76 \mathrm{~kJ} / \mathrm{m}^{3}$ and bottom $75.25 \mathrm{~kJ} / \mathrm{m}^{3}$, at $20 \%$ load. Similarly, the maximum acceleration is noted in head $203.6 \mathrm{~kJ} / \mathrm{m}^{3}$, crank $130.8 \mathrm{~kJ} / \mathrm{m}^{3}$ and bottom $91.83 \mathrm{~kJ} / \mathrm{m}^{3}$ at $100 \%$ load. 


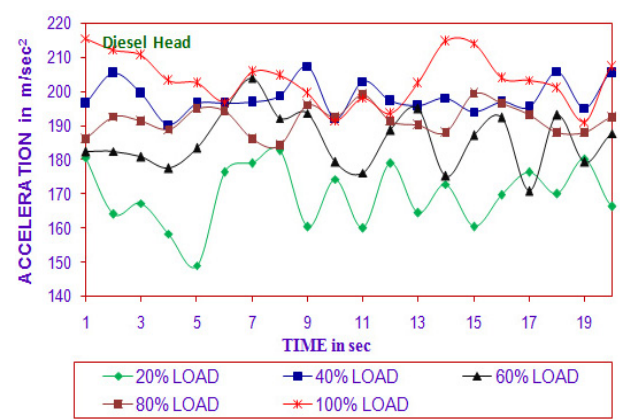

Fig. 2. Time vs acceleration (diesel head in all load)

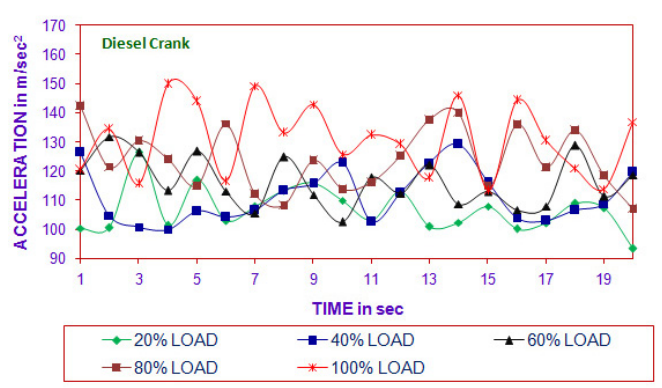

Fig. 4. Time vs acceleration (diesel crank in all load)

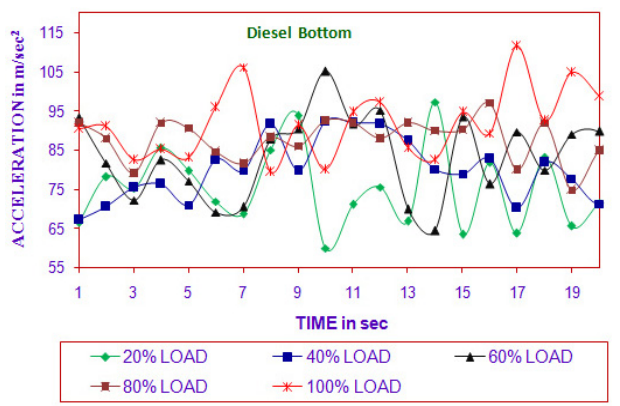

Fig. 6. Time vs acceleration (diesel bottom in all load)

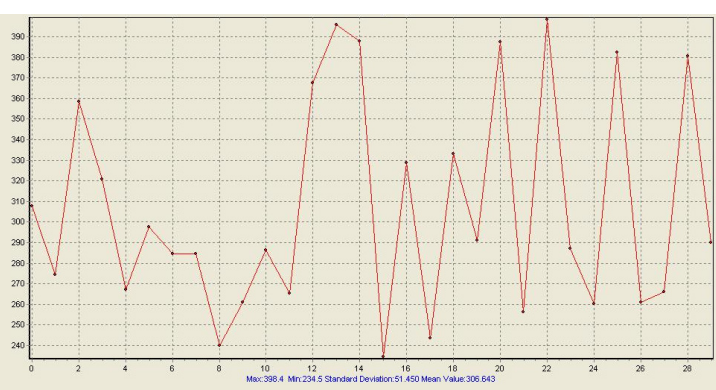

Fig. 3. Time vs acceleration (diesel head in $20 \%$ load)

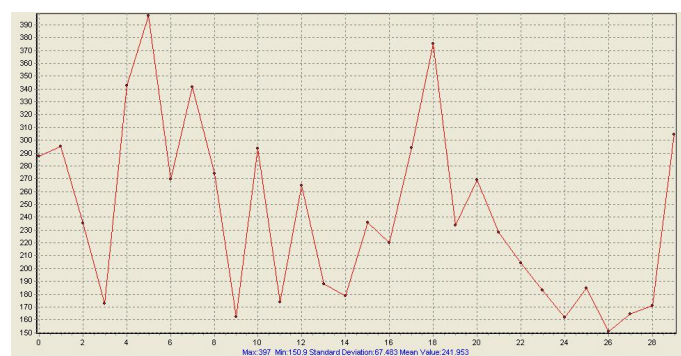

Fig. 5. Time vs acceleration (diesel crank in $20 \%$ load)

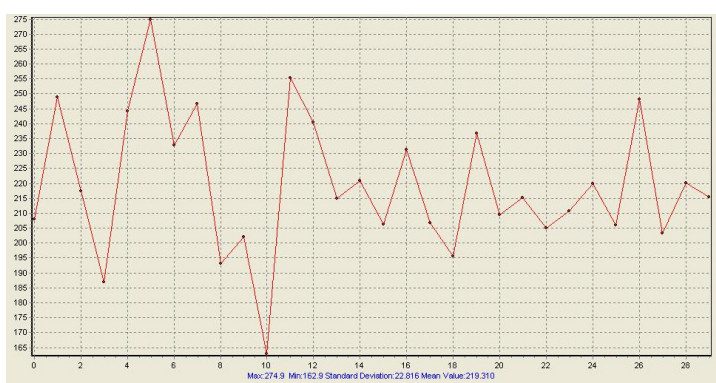

Fig. 7. Time vs acceleration (diesel bottom in $20 \%$ load)

\subsection{Vibration analysis with EEGAO}

With the evaluation of vibration values from Figs. 8 to 13, it is observed that in biodiesel (EEGAO) with blend of B20 in three different place of the engine such as head, crank and bottom. Load at $20 \%$ shows minimum acceleration in B20 blend. In Table 2, for bottom, minimum acceleration is noticed at $20 \%$ load and maximum at $100 \%$ load compared to both of the head and crank. This may due to variation of cylinder pressure inside the combustion chamber. Also, rapid variation and oscillation of cylinder pressure in combustion chamber are lower in B20 blend compared to other blends, thus leads to lower acceleration. The maximum acceleration is attained at head of the engine for biodiesel while compared to the crank and bottom. This is due to combustion taking place in cylinder head $[17,18]$. In combustion chamber, rapid variation of cylinder pressure results, showed the peak acceleration in head position. The combustion of the fuel inside the cylinder depends on different constraint such as physical properties and chemical properties (flash point, fire point, cetane number and viscosity). The lower vibration is found at 
$20 \%$ load in B20EEGAO blends in all position. As the load increases air fuel ratio reduces, this leads to incomplete combustion in combustion chamber [19]. In complete combustion, the vibration of the engine is noted. As the diesel quantity in the blends increases, the quantity of fuel taking part in the uncontrolled combustion stage of the mixture reduces, which results in a better pressure rise. It is concluded that low viscosity, more oxygen content and good volatility of B20EEGAO blend, lead to good atomization and mixture preparation with air during the ignition period. The vibration in head position in the diesel engine depends upon the combustion rate in the initial stages. The mean acceleration in head was $235.7 \mathrm{~m} / \mathrm{sec}^{2}$ for B20EEGAO blend, mean acceleration in crank was $141.10 \mathrm{~m} / \mathrm{sec}^{2}$ for B20EEGAO blend, and mean acceleration in bottom was $92.18 \mathrm{~m} / \mathrm{sec}^{2}$ for B20EEGAO blend at $20 \%$ load.

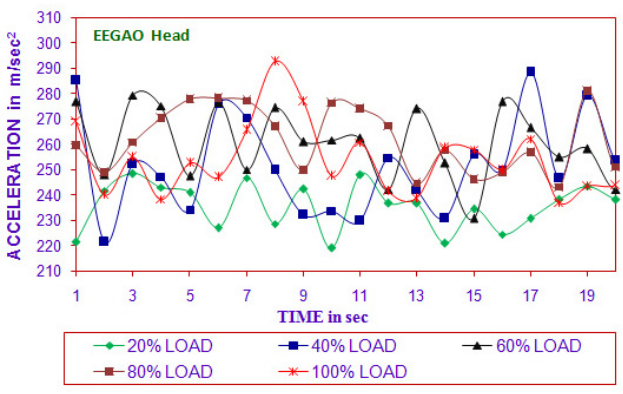

Fig. 8. Time vs acceleration (B20EEGGAO head in all load)

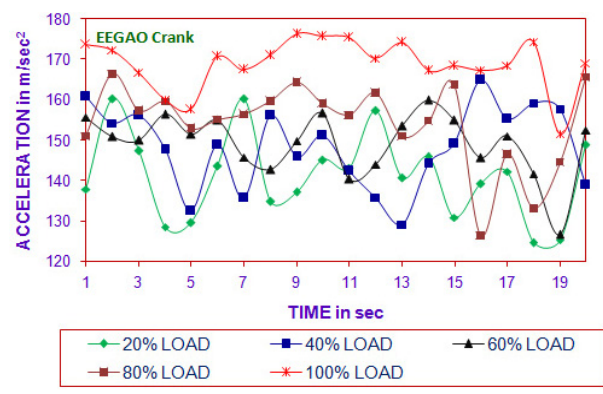

Fig. 10. Time vs acceleration (B20EEGAO crank in all load)

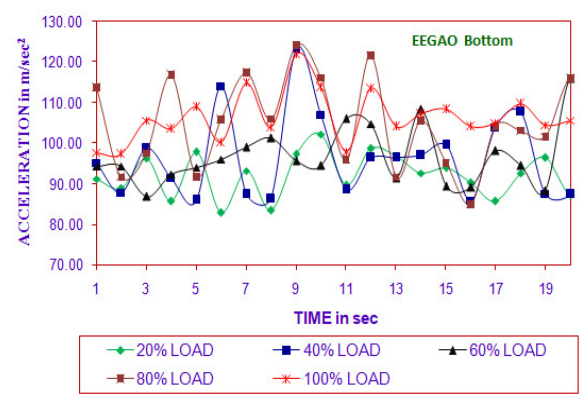

Fig. 12. Time vs acceleration (B20EEGAO bottom in all load)

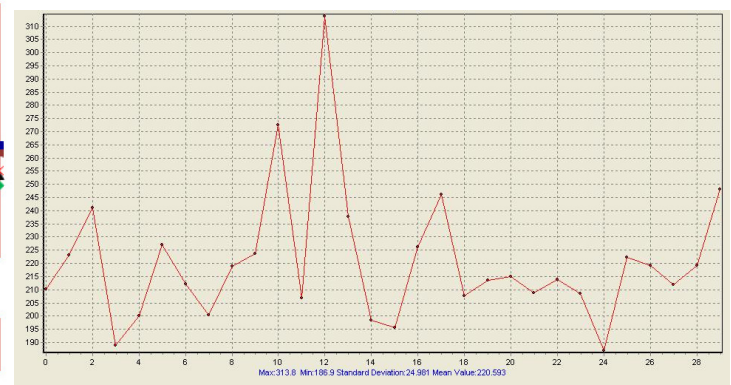

Fig. 9. Time vs acceleration (B20EEGGAO head in $20 \%$ load)

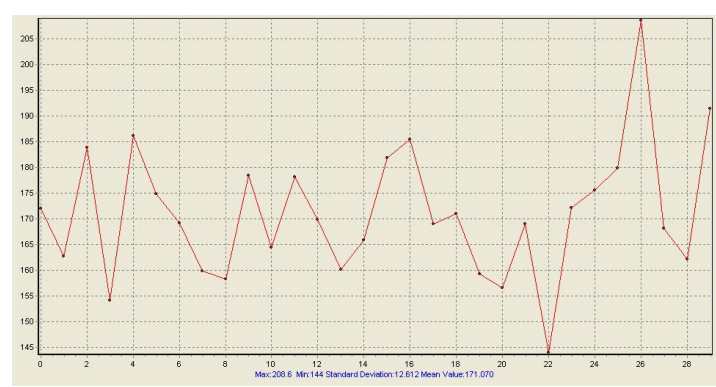

Fig. 11. Time vs acceleration (B20EEGAO crank in $20 \%$ load)

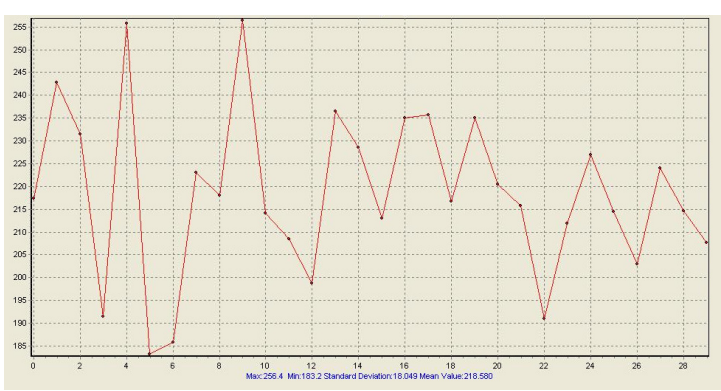

Fig. 13. Time vs acceleration (B20EEGAO bottom in $20 \%$ load)

\subsection{Vibration analysis with (MWCNT30ppmB20EEGAO)}

With the evaluation of vibration values from Figs. 16 to 19 , it is observed that for four different 
biodiesel (MWCNTB2030ppmEEGAO) in different load (20\%, $40 \%, 60 \%, 80 \%$ and $100 \%)$ with three different place of the engine such as head, crank and bottom. The acceleration is minimal in the MWCNT30ppmB20EEGAO at $20 \%$ load compared to other blends. The mean and maximum vibration values are listed in table 2 . For bottom, the lower acceleration is noticed at MWCNT30ppmB20EEGAO at $20 \%$ load and maximum at $100 \%$ load.

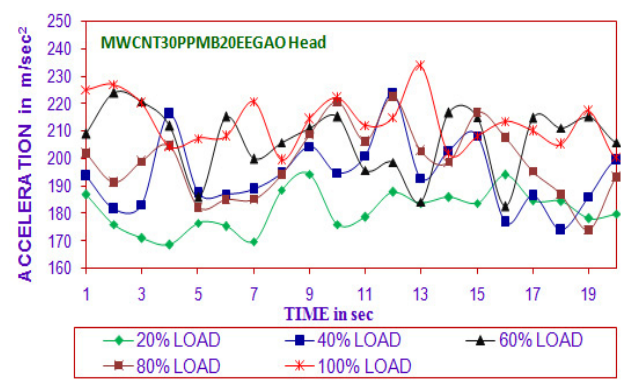

Fig. 14. Time vs acceleration

(MWCNT30ppmB20EEGAO head in all load)

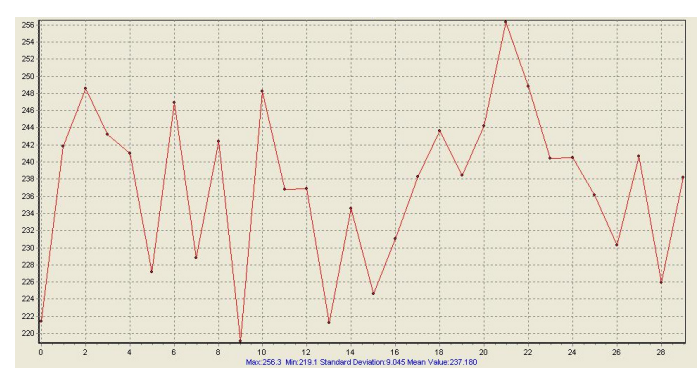

Fig. 15. Time vs acceleration (MWCNT30ppmB20EEGAO head $20 \%$ load)

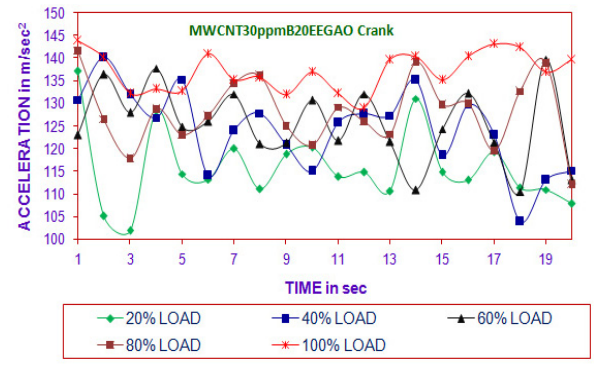

Fig. 16. Time vs acceleration (MWCNT30ppmB20EEGAO crank in all load)

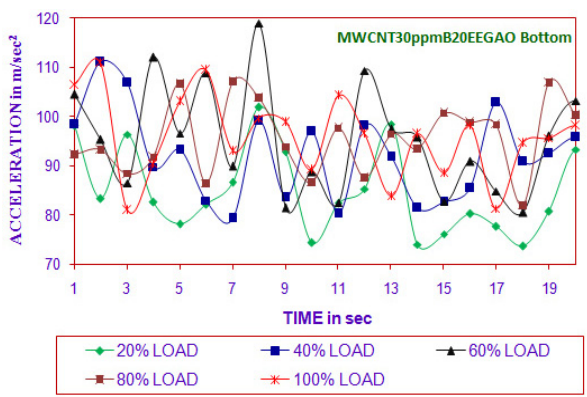

Fig. 18. Time vs acceleration (MWCNT30ppmB20EEGAO bottom in all load)

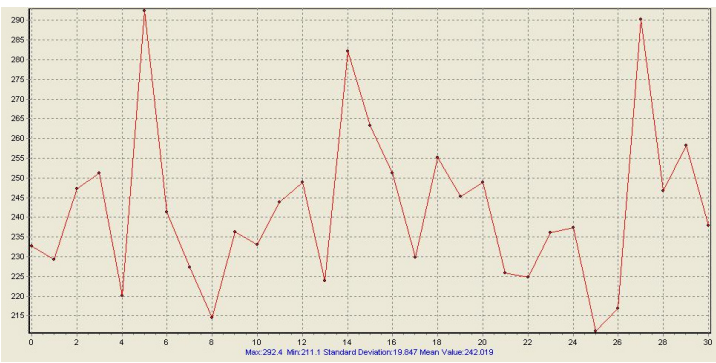

Fig. 17. Time vs acceleration (MWCNT30ppmB20EEGAO crank in $20 \%$ load)

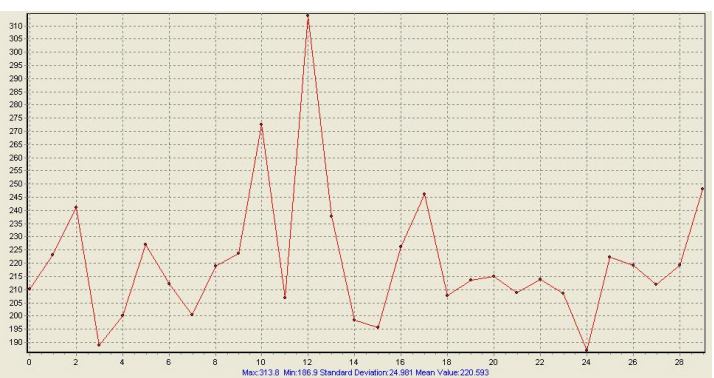

Fig. 19. Time vs acceleration (MWCNT30ppmB20EEGAO bottom in $20 \%$ load)

Consequently, the acceleration is caused by various reasons such as injection parameter and cetane number. The acceleration is not only caused by above two reasons, it may also be possible because of fire point, flash point, viscosity, molecule structure, physical properties, thermal properties and chemical properties. MWCNT fuel is a oxygenated fuel. The acceleration is decreased with higher contented of oxygenated fuel and also fuel spraying and fuel structure has an impact. Vibration reduction could be attributed to short ignition delay and the improved ignition characteristics. In MWCNTB20EEGAO blend, it has advanced combustion, because surface volume ratio was higher in MWCNT [20]. This leads to improve the atomization of fuel, thus enhance the combustion and heat transfer rate, it leads to reduced vibration. In this perspective, 
the catalytic activity of MWCNT could have improved, due to the existence of high surface area and active surfaces. The mean acceleration in head was $181.1 \mathrm{~m} / \mathrm{sec}^{2}$ for MWCNT30ppmB20EEGAO blend at $20 \%$ load. The mean acceleration in crank was $115.1 \mathrm{~m} / \mathrm{sec}^{2}$ for MWCNT30ppmB20EEGAO blend at $20 \%$ load. The mean acceleration in bottom was $84.98 \mathrm{~m} / \mathrm{sec}^{2}$ for MWCNT30ppmB20EEGAO blend at $20 \%$ load.

Table 2. Summation of details for optimal for EEGAO and MWCNT30ppmB20EEGAO

\begin{tabular}{|c|c|c|c|c|c|c|c|c|c|c|c|c|}
\hline \multirow{4}{*}{ Fuel } & \multicolumn{12}{|c|}{ Acceleration in $\mathrm{m} / \mathrm{sec}^{2}$} \\
\hline & \multicolumn{4}{|c|}{ Head } & \multicolumn{4}{|c|}{ Crank } & \multicolumn{4}{|c|}{ Bottom } \\
\hline & \multicolumn{2}{|c|}{$20 \%$ load } & \multicolumn{2}{|c|}{$100 \%$ load } & \multicolumn{2}{|c|}{$20 \%$ load } & \multicolumn{2}{|c|}{$100 \%$ load } & \multicolumn{2}{|c|}{$20 \%$ load } & \multicolumn{2}{|c|}{$100 \%$ load } \\
\hline & $\operatorname{Max}$ & Mean & $\operatorname{Max}$ & Mean & Max & Mean & $\operatorname{Max}$ & Mean & Max & Mean & Max & Mean \\
\hline Diesel & 180.7 & 169.5 & 215.8 & 203.6 & 117 & 106.7 & 149.2 & 130.8 & 97.2 & 75.25 & 111.6 & 91.83 \\
\hline B20EEGAO & 248.6 & 235.7 & 292.8 & 254.03 & 160.2 & 141.10 & 176.3 & 168.65 & 102.26 & 92.18 & 122.06 & 106.40 \\
\hline $\begin{array}{l}\text { MWCNT30ppm } \\
\text { B20EEGAO }\end{array}$ & 188.4 & 181.08 & 233.5 & 213.19 & 131.04 & 115.91 & 140.8 & 137.03 & 101.9 & 84.98 & 110.8 & 96.01 \\
\hline
\end{tabular}

\section{Conclusions}

The minimal vibration is seen in each of the three positions for MWCNT30ppmB20EEGAO at $20 \%$ load and maximum is noted at $100 \%$ load. Subsequently, vibration might be influenced by different factors like fuel cetane number, and injection advance. Vibration decrease could be credited to short ignition delay and the enhanced ignition attributes of MWCNT. Thus, prompting higher catalytic activity because of their higher surface to volume proportion and improving fuel air blending in the burning chamber. The second least value of vibration is seen in diesel. The homogeneous charge so obtained results in appropriate and complete combustion. Thus, the results show that the delay period was limited, and engine vibrations measured were diminished. The vibration of B20EEGAO biodiesel fuel is higher than that of diesel fuel. Likewise, for pure biodiesel fuel, viscosity is more than diesel fuel. Results also confirms that vibration was altogether influenced by engine load and fuel blend. The average peak vibration can be decreased by adding the MWCNT. The experimental analysis is conducted in the same DI diesel engine for all fuels used in this work. For all the fuels used, the vibration produced does not affect the engine parts, whereas it is noted that for MWCNT30ppmB20EEGAO the vibration is minimal compared to diesel and B20EESAO. So, it is concluded that MWCNT30ppmB20EEGAO is suitable to increase the life of the engine.

\section{References}

[1] Manieniyan V., Sivaprakasam S. Vibration analysis in DI diesel engine using diesel and biodiesel. International Journal of Engineering Trends and Technology, Vol. 4, 2013, p. 433-439.

[2] Foumani Mahmoud S., Amir Khajepour, Mohammad Durali Optimization of engine mount characteristics using experimental/numerical analysis. Modal Analysis, Vol. 9, Issue 10, 2003, p. 1121-1139.

[3] Liu Xianhua, Randall Robert B., Antoni Jerome Blind separation of internal combustion engine vibration signals by a deflation method. Mechanical Systems and Signal Processing, Vol. 22, Issue 5, 2008, p. 1082-1091.

[4] Kadam, Dnyaneshwar V., Sangram Jadhav D. Optimization of vibration, performance and emission of CI engine operated on Simarouba biodiesel using Taguchi and multiple regression analysis. SAE Technical Paper 2017-01-2137, 2017, https://doi.org/10.4271/2017-01-2137.

[5] Deivajothi P., Manieniyan V., Sivaprakasam S. Experimental investigation on the effect of thermal cracked carbon filtered fatty acid biodiesel on engine performance and exhaust emission. International Journal of Engineering Trends and Technology, Vol. 38, 2016, p. 330-333.

[6] Jindal S. Vibration signatures of a biodiesel fueled CI engine and effect of engine parameters. International Journal of Energy and Environment, 2012, p. 151-160. 
[7] Taghizadeh Alisaraei Ahmad, Ghobadian Barat, Hashjin Teymour Tavakoli, Mohtasebi Seyed Saeid Vibration analysis of a diesel engine using biodiesel and petrodiesel fuel blends. Fuel, Vol. 102, 2012, p. 414-422.

[8] Wongchai Boonthum, Porranat Visuwan, Sathaporn Chuepeng The vibration analysis of diesel engine with hydrogen-diesel dual fuel. American Journal of Applied Sciences, Vol. 10, Issue 1, 2013, p. 8-14.

[9] Ftoutou Ezzeddine, Mnaouar Chouchane Injection fault detection of a diesel engine by vibration analysis. International Conference Design and Modeling of Mechanical Systems, 2017.

[10] Guo Zhi-Wei, Yuan Cheng-Qing, Bai Xiu-Qin, Yan Xin-Ping Experimental study on wear performance and oil film characteristics of surface textured cylinder liner in marine diesel engine. Chinese Journal of Mechanical Engineering, Vol. 31, 2018, p. 52.

[11] Ostman Fredrik, Toivonen Hannu T. Torsional system parameter identification of internal combustion engines under normal operation. Mechanical Systems and Signal Processing, Vol. 25, Issues 4-2011, 2011, p. 1146-1158.

[12] Mohtasebi Seyed Saeid, Ghasemi-Varnamkhasti Mahdi, Mohtasebi S. M., Zabolestani Masoud Investigation of internal combustion engine vibrations in order to reduce noise using a developed model. Journal of Food, Agriculture and Environment, Vol. 7, Issues 3-4, 2009, p. 915-919.

[13] Zhang Jian, Liu Chang-Wen, Bi Feng-Rong, Bi Xiao-Bo, Yang Xiao Fault feature extraction of diesel engine based on bispectrum image fractal dimension. Chinese Journal of Mechanical Engineering, Vol. 31, 2018, p. 40.

[14] Carlucci A. P., Chiara F. F., Laforgia D. Analysis of the relation between injection parameter variation and block vibration of an internal combustion diesel engine. Journal of Sound and Vibration, Vol. 295, Issues 1-2, 2006, p. 141-164.

[15] Heidary B., Hassan Beygi S. R., Ghobadian B., Taghizadeh A. Vibration analysis of a small diesel engine using diesel-biodiesel fuel blends. Agricultural Engineering International, Vol. 15, Issue 3, 2013, p. 117-126.

[16] Kirk Gordon R., Kornhauser Alan A., Sterling John, Alsaeed Ali Turbocharger on-engine experimental vibration testing. Journal of Vibration and Control, Vol. 16, Issue 3, 2010, p. 343-355.

[17] Jiang J., Gu F., Gennish R., Moore D. J., Harris G., Ball A. D. Monitoring of diesel engine combustions based on the acoustic source characterisation of the exhaust system. Mechanical Systems and Signal Processing, Vol. 22, Issue 6, 2008, p. 1465-1480.

[18] Periyasamy Sivanandi, Alwarsamy Thirunarayanaswamy Combined effects of inertia and pressure on engine vibration. Journal of Vibration and Control, Vol. 19, Issue 16, 2013, p. 2469-2480.

[19] Yildirim Sahin, Erkaya Selcuk, Eski Ikbal, Uzmay Ibrahim Noise and vibration analysis of car engines using proposed neural network. Journal of Vibration and Control, Vol. 15, Issue 1, 2009, p. $133-156$.

[20] Velumani V., Manieniyan V., Sivaprakasam S. Performance and emission characteristics of a DI diesel engine with vegetable oil refinery waste sunflower acid oil. International Journal of Recent Innovation in Engineering and Research, Vol. 3, Issue 3, 2018, p. 7-11.

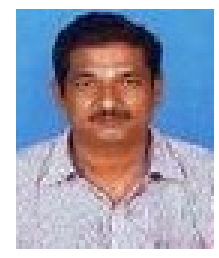

V. Velumani has doing his doctoral degree in Mechanical Department of Annamalai University under the guidance of Prof. Dr. S. Sivaprakasam. He has his under graduate level degree graduation from Annamali University, Tamilnadu, India. He has nearly 10 years of working experience which includes 10 years in teaching, 5 years in research. To his research interest, he has nearly publications 3 international journals. His area of interest is thermal and combustion engineering.

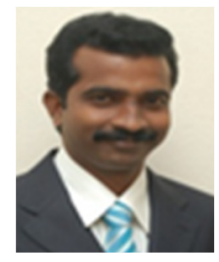

V. Manieniyan has completed B.E. (mechanical) undergraduate in 2001 from Annamalai University and post graduate in M.E (thermal power engineering). After graduation he got industrial exposure in thermal power plant as Assistant Engineer. Later he has joined as a Lecturer in Annamalai University, Annamalai Nagar, Tamilnadu, where his current teaching experience is 13 years. He received his Ph.D. in 2014. He has published many papers in national/international conferences and also in international journals. In future he is planning to involve himself more in the research area of biodiesel. 
Dr. S. Sivaprakasam is Associate Professor in mechanical engineering at Annamalai University, Tamil Nadu. He received B.E Degree in Mechanical Engineering and post graduate in M.E (thermal power engineering) from Annamalai University. He then stared his teaching career at his alma mater, with special interest in emission controls in diesel engine along with subjects like alternate fuel and machine design. He received his Ph.D. in 2006. He has published 25 paper in both international and national journal an the subject of alternative fuels with emphasis on biodiesel. He is a member of ISTE, SAE, The Combustion Institute and ENFUSE. 